\title{
Educación sexual integral, Marco Berger y Ausente. Miradas en conflicto desde una didáctica de la comunicación ${ }^{*}$
}

\author{
Diego A. Moreiras ${ }^{\star *}$
}

Recibido: 2015-08-26 Enviado a pares: 2015-08-15

Aprobado por pares: 2015-09-21 Aceptado: 2015-10-01

\section{Resumen}

Este escrito es parte de las preocupaciones del equipo de Investigación de la Dra. Ximena Triquell $1^{1}$, y en ese marco inscribe la pesquisa en una perspectiva sobre conflictos sociales en discursos audiovisuales, en este caso, aquellos vinculados con la sexualidad en contextos escolares. En este marco, y con el objetivo de dar cuenta de conflictos vinculados a la sexualidad, este artículo presenta en primera instancia un análisis semiótico del filme Ausente, de Marco Berger. En segundo lugar, busca encuadrar estas reflexiones anteriores en una perspectiva que denominamos didáctica de la comunicación, que consideramos se encuentra actualmente en construcción. En tercer lugar, a partir de lo anterior, propone una reflexión oblicua sobre la educación sexual integral en Argentina.

Palabras clave: cine; semiótica; didáctica de la comunicación; educación sexual integral; ausente; Marco Berger; Ley 26.150.

* El presente escrito se origina como parte del trabajo del autor en el GRUPO DE ESTUDIOS DE LA IMAGEN (GEI) y en el Proyecto de Investigación "Imágenes en conflicto": Construcciones audiovisuales de la conflictividad social en la Argentina contemporánea. Segunda etapa, ambos dirigidos por la Dra. Ximena Triquell y codirigidos por el magíster Santiago Ruiz. El Proyecto ha sido presentado y financiado por la Secretaria de Ciencia y Técnica de la Universidad Nacional de Córdoba, Argentina. El mismo cuenta con la aprobación según Resolución Rectoral 1565/14 (UNC). Este escrito es producto de mi participación como miembro de la Cátedra Didáctica de la Comunicación I del Profesorado en Comunicación Social, de la Escuela de Ciencias de la Información, Universidad Nacional de Córdoba, coordinada por la Prof. Fabiana Castagno. Por otro lado, también de mi trabajo dentro del Programa de Investigación CULTURA(S) Y TECNOLOGÍA(S): ESTUDIOS DE LA MEDIATIZACIÓN EN ESCENARIOS EDUCATIVOS, dirigido por la Dra. Eva Da Porta y coordinado por la Esp. Verónica Plaza Schaefer. Radicado en el Centro de Estudios Avanzados, de la misma casa de estudios.

** Profesor en Primer y Segundo Ciclo de EGB, licenciado en Comunicación Social y magíster en Investigación Educativa. Actualmente se desempeña como docente regular del Profesorado en Comunicación Social de la Escuela de Ciencias de la Información, Universidad Nacional de Córdoba. Se encuentra finalizando su Tesis de Doctorado en Semiótica con una beca del Consejo Nacional de Investigaciones Científicas y Técnicas (CONICET) de Argentina en temas vinculados a lo audiovisual en educación. Escuela de Ciencias de la Información, Universidad Nacional de Córdoba. diegoamoreiras@gmail.com 


\title{
Sexual Education Policy, Marco Berger and Absent. Regards in conflict from the Communication Didactics (today under construction)
}

\begin{abstract}
Firstly, this article presents a mainly semiotic analysis of the filme Absent, by Marco Berger. Secondly, and from then on, it proposes some oblique considerations about Argentina's Comprehensive Sexual Education Policy. In the third place, it seeks to focus these previous reflections in a perspective, actually under construction, that we call Communication Didactics. Finally, this paper is part of the concerns of the Research Team led by Dr. Ximena Triquell. In that institutional frame, we inscribe these results in a larger inquiry, whose topics include social conflicts in audiovisual discourses. In our case, the attention is centered in sexual conflicts in educational sceneries.
\end{abstract}

Key words: sexual educational policy; absent; Marco Berger; cinema; semiotics; communication didactics; Law 26.150. 


\section{Ideas preliminares}

El mercado avanza incluso allí donde se producen fisuras. Las estrellas cinematográficas (norteamericanas, pero también de otras latitudes) han dado muestras suficientes de utilidad para las industrias de la comunicación, sobre todo audiovisual. Las estrellas del firmamento hollywoodense, por ejemplo, nunca fueron exclusivamente femeninas y ciertamente no lo son ahora. Así, cámaras que se detienen en protagonistas masculinos no constituyen novedad alguna. Por citar solo un ejemplo clásico proveniente de nuestra cinematografía nacional, Leonardo Favio con un memorable travelling alrededor del rostro de Alfredo Alcón en Nazareno Cruz y el lobo (1975) ya lo hacía en los setenta (14:59 min y ss.). En nuestros tiempos, diferentes de los tiempos de ese cine de Favio, vemos gestos similares de manera continuada, probablemente con otros fines. Ante esto, entonces, no estamos habilitados a encontrar gestos de resistencia. Tampoco nos olvidamos de que aquello que es dado a ver puede, en instancias de recepción, ser subvertido tácticamente.

Ahora, en los largometrajes y especialmente en los cortometrajes de Marco Berger, en cambio, nos encontramos con un plus, una pequeña diferencia: cuerpos masculinos son dados a ver por la cámara, en muchos casos por cámaras a media altura, coincidentes justo con las partes medias de estos cuerpos, en muchos casos en planos fijos, de encuadres reducidos, que no dejan lugar a la mirada esquiva. Sumado a esto, sin embargo, en uno u otro momento del encuadre, la mirada de la cámara coincide con la de alguno de los personajes de la trama. Y estos personajes, indefectiblemente, son masculinos. Se trata de jóvenes (y) hombres mirando a media altura a jóvenes (y) hombres, en algunos casos, en ropa interior. Berger en este sentido estrecha las posibilidades de uso (cfr. Eco, 1987: 80 y ss.) de cada una de estas obras que él ha creado. Así, por lo menos por momentos, la mirada de cualquier espectador coincide con la de algún personaje masculino que mira más o menos furtivamente, las partes medias de otro personaje del mismo sexo.

La posibilidad para un espectador cualquiera (sin diferenciar sexos ni géneros) de reconocer en esa mirada masculina incorporada dentro de la diégesis un deseo propio puede ser una situación nueva. De este modo, el cine de Berger propone tiempos muertos, encuadres fijos y pausas narrativas que, alejadas tanto del cine mainstream como del cine pornográfico, muestran, en relación con estos, esa diferencia que mencionábamos antes.

Si aceptamos este punto de partida, ¿cuál podría ser la relación de esta diferencia con una didáctica de la comunicación ${ }^{2}$ (que deberemos considerar aún en lenta construcción)? Una didáctica semejante, entendida como una reflexión-acción sobre los modos de generar propuestas de enseñanza en el ámbito de la comunicación, nos auxiliará doblemente: en

2 Profesor en Primer y Segundo Ciclo de EGB, licenciado en Comunicación Social y magíster en Investigación Educativa. Actualmente se desempeña como docente regular del Profesorado en Comunicación Social de la Escuela de Ciencias de la Información, Universidad Nacional de Córdoba. Se encuentra finalizando su Tesis de Doctorado en Semiótica con una beca del Consejo Nacional de Investigaciones Científicas y Técnicas (CONICET) de Argentina en temas vinculados a lo audiovisual en educación. Escuela de Ciencias de la Información, Universidad Nacional de Córdoba. diegoamoreiras@gmail.com 
la manera de leer el filme considerado y en ciertas perspectivas teóricas provenientes de campos aledaños que nos permitirán analizarlo.

Y lo que nos permitirá sostener/ proponer esta didáctica de la comunicación en construcción es el reconocimiento de una re-politización posible como espectadores frente a ciertas imágenes que marcan alguna diferencia a partir de una mirada oblicua ${ }^{3}$. La cuestión en torno a una didáctica de la comunicación ingresa aquí bajo la forma de una interpretación (cfr. Eco, 1987, p. 69 y ss.) específica de ciertas imágenes y una reflexión sobre ciertas miradas que conducen a la potencial utilidad pedagógica de un conflicto. En ese sentido, esperamos que un escrito como este pueda ser leído también por docentes y pueda colaborar en la reflexión sobre su trabajo, especialmente en la selección de materiales y recursos para el trabajo en el aula.

La educación sexual integral (ESI, de ahora en más), promulgada con fuerza de ley en nuestro país en el año 2006 (Ley 26.150), es en muchos sentidos una materia pendiente en (¿algunas de?) las escuelas de nuestro país, en gran medida, y lo sostenemos como una hipótesis que no podremos probar en el marco de este escrito, debido a que uno de los puntos centrales de una ESI posible tiene a la propia sexualidad, a las creencias y a la propia mirada de los docentes como (posible) obstáculo. De este modo, interrogarnos sobre los usos que podemos hacer de ciertas imágenes y sobre los modos en que ciertas miradas nos habitan y nos construyen resulta un trabajo necesario si nos asumimos profesionales de la docencia. Y una didáctica de la comunicación puede ayudarnos en este recorrido, como decíamos antes, a la vez que le ayudamos a ella a constituirse.

En el presente escrito nos propondremos dar cuenta de la potencialidad pedagógica de una obra como las de Berger, pensando en nuestras obligaciones en tanto docentes para con la ESI. Argumentaremos que justamente la complejidad y conflictividad de su planteo habilita una operación didáctica que, como comunicadores, podemos realizar sobre esa obra para hacerla estallar y acercarla a nuestros intereses didácticos.

Estas ideas de inicio son las que invitan a un trabajo en profundidad con Ausente (2011), el segundo filme de Marco Berger y algunas menciones menores de sus otras obras (cortos y largometrajes).

\section{Laura Mulvey, la cámara y las tres miradas en el cine narrativo clásico}

Mulvey (2001, p. 367) afirma que el cine narrativo clásico de Hollywood se asienta, de modo general y en primer lugar, sobre el placer que el acto de mirar tiene para los sujetos

3 La idea de mirada oblicua o reflexión oblicua tiene diversas trayectorias y no necesariamente muchos desarrollos teóricos. German Rey (2007, p. 12) asocia esa idea de la direccionalidad de la mirada con autores diferentes, desde Roger Caillois a Clifford Geertz, por ejemplo. En un contexto literario, Norma Garza (2002) afirma: "La mirada oblicua es la que está atravesada por el error, la duda y la sospecha, es la que pone en cuestión lo que se mira o la que hace pensar en la posibilidad de otra respuesta a lo establecido, pensar que no hay verdades definitivas" (p. 177). Nuestras reflexiones iniciales en torno a una didáctica de la comunicación están encaminadas hacia la idea de la oblicuidad de una mirada como herramienta de trabajo y son parte de intereses actualmente en desarrollo. 
(escopofilia). Además, afirma que cuando ese acto de mirar tiene como objeto privilegiado a la figura humana, se trata de una mirada narcisista que contribuye a la constitución del ego, ya que se trata de una mirada hacia aquello que resulta conocido, aquello que presenta las mismas características que posee el sujeto que mira (su humanidad). De esto, ella deriva los análisis en torno a la mujer como espectáculo y como significante clave en el sistema de estrellas creado por el cine hollywoodense clásico.

Así, Mulvey consigue argumentar en 1975, fecha de la primera publicación de este artículo, que la mujer es dada como objeto para una mirada que necesariamente es masculina y que se corresponde tanto con la de los personajes de la historia que se desarrolla en la pantalla como con la de los espectadores que asisten al filme. El momento de la exhibición de la mujer en este cine clásico se corresponde con una pausa en el devenir narrativo en beneficio de una mera contemplación erótica del objeto-mujer, al punto que, a través del propio artificio de la construcción fílmica, en muchas oportunidades la mirada del personaje masculino de la historia logra "(con)fundirse" con la del espectador masculino del propio filme, mediante, por ejemplo, el recurso al "artificio de la showgirl" (Ibíd., p. 371).

El espectador no solo se identifica con la mirada del personaje masculino, sino también con su poder de controlar los acontecimientos narrativos del filme, de forma que, según Mulvey, se produce una "satisfactoria sensación de omnipotencia" (Ibíd., p. 371) en ellos. Como queda en evidencia, todo el dispositivo técnico del filme tiende a producir esta identificación masculina, a partir de un acto de voyeurismo que coloca a la mujer en situación de objeto de la mirada.

Estos desarrollos que hemos esbozado aquí resultan suficientes para poner de relieve la importancia que la mirada tiene en el cine: "Lo que define al cine es el lugar de la mirada, la posibilidad de variarla y de hacerla patente" (Mulvey, 2001, p. 376). De este modo, podemos reconocer tres miradas coexistiendo en este cine clásico que analiza la autora: "la de la cámara cuando graba los acontecimientos, la del público cuando contempla el producto acabado, y la de los personajes que se miran unos a otros dentro de la ficción de la pantalla" (Ibíd., p. 377). Este triple juego de miradas permite explicar los procesos de escopofilia y de identificación propuestos por Mulvey.

Hasta aquí, no nos hemos detenido, con todo, en los objetivos que ella persigue con su propuesta de utilizar las herramientas del psicoanálisis para analizar estos filmes. Busca, ni más ni menos, aportar herramientas para el análisis del placer y la belleza en el cine, y a partir de eso, contribuir para su destrucción (p. 367). ¿De qué manera? La autora afirma que, mediante el reconocimiento y la exposición de las dos primeras miradas, tradicionalmente invisibilizadas por el cine convencional (en el sentido de que el dispositivo trabaja para que no se perciban), se contribuye a socavar esa mirada voyeurista-escopofílica (p. 377).

Ahora bien, toda vez que este instrumental de análisis, construido a los fines mencionados, resulta adecuado para el tipo de cine objeto de las reflexiones de Mulvey, debemos reconocer que requiere de algunas revisiones cuando buscamos utilizarlo para el análisis del cine de Marco Berger. Mientras que las reflexiones en torno a la castración 
que la figura femenina pone en escena deberían ser dejadas entre paréntesis, aquellas referidas a la escopofilia, no obstante, consideramos que siguen funcionando, quizá con algunas diferencias.

En primer lugar, si consideramos que los cuerpos dados a ver son masculinos, podríamos prever una inversión de los planteos de la autora: esos cuerpos estarían destinados a una mirada femenina, heterosexual. Berger rompe esta previsión: sitúa en la diégesis cuerpos masculinos que son mirados por jóvenes (y) hombres. Y, además, sus filmes proponen habitualmente que, a partir del juego de cámaras, la mirada del espectador también se identifique con ese personaje masculino mirando cuerpos masculinos. El acto de voyeurismo se sostiene; sin embargo, cabe preguntarnos si, aún a pesar de sostener las pausas narrativas para la mirada escopofílica sobre un cuerpo-objeto (masculino en este caso), el cine de Berger no realiza una ruptura desde dentro del propio dispositivo, al proponerle al espectador una identificación no esperada. Sobre esta hipótesis tampoco avanzaremos más aquí, sino que en este trabajo nos limitaremos a utilizar las categorías de las tres miradas propuestas por Laura Mulvey en el artículo ya citado para el análisis de la segunda obra de Marco Berger (y algunas consecuencias de su uso en propuestas educativas vinculadas a la ESI).

\section{Ausente, en particular ${ }^{4}$}

En nuestra cinematografía nacional, sobre todo en la última década y media, encontramos una serie de películas que han planteado relaciones afectivas y sexuales de niños y adolescentes entre sí, por ejemplo, Glue (Dos Santos, 2006), El verano de la boyita (Solomonoff, 2009), XXY (Puenzo, 2007). En ellas, el conflicto principal pareciera afectar a los protagonistas, en tanto portadores de pasiones y de rasgos que recién comienzan a descubrir y a explorar en sí mismos justamente por ser adolescentes.

Esto mismo es válido también para relaciones que incluyen adultos. Encontramos dentro y fuera de nuestro país una tradición de historias afectivas y sexuales entre adultos y adolescentes - de las cuales, quizá la más conocida sea Lolita (Nabokov, 1987), primero en su versión literaria-, o en un rango más estrecho, historias de este orden entre docentes y alumnos: Notes on a scandal, de Richard Eyre (2006), como un ejemplo del cine foráneo. En estas últimas, en cambio, los conflictos son menos resultado de una problematización de los personajes sobre sí mismos que el resultado del "escándalo" social (y legal) que estos vínculos generan (basta retornar al título del filme de Eyre).

¿Qué es lo que amerita, en todo caso, detenernos en el filme de Marco Berger? ¿Qué hay en Ausente de "nuevo" o interesante?

4 Para la aproximación metodológica de este trabajo, presente de aquí en adelante, hemos utilizado específicamente las obras de Triquell (coord.) (2011) y de Ilardo (2014). Ambos trabajos parten de una reelaboración de las propuestas narratológicas clásicas de la semiótica de los sesenta y de los estudios sobre cine, fundamentalmente de los ochenta y noventa. 
El filme Ausente (2011) de Marco Berger transcurre, en promedio, mitad del tiempo en ámbitos públicos educativos ${ }^{5}$ y mitad en ámbitos privados familiares. Sin embargo, el conflicto narrativo mayor deviene de los roles que los dos protagonistas principales ejercitan en el espacio público, fundamentalmente educativo. No obstante, como es de esperar, estos roles generan mayor tensión dramática cuando las acciones se desarrollan en el interior de un departamento, en un ámbito privado-íntimo. Así, lo que detona el conflicto narrativo son los roles temáticos de "estudiante" y "docente", en tanto los sujetos que los llevan adelante se ven forzados a interactuar por fuera del ámbito escolar y esa interacción está mediada, además, por el deseo y la tensión sexual explicitada, como veremos, a partir de las imágenes y las miradas.

\section{Los conflictos y lo político}

En el punto de partida para este trabajo se encuentra la manera en que Eliseo Verón (1987) entiende la relación entre discursos y realidad: lejos de suponer una relación transparente (directa, linealmente determinada) entre ambos, Verón nos propone entender que la segunda está construida (y en permanente construcción) a partir de los primeros. Recuperando los aportes de Charles S. Peirce, Ximena Triquell y Santiago Ruiz (2014) lo expresan de este modo:

Esta realidad/objeto dinámico es por un lado la que determina que el signo tome un aspecto de ella para representar, pero a su vez es la que se va construyendo en el tiempo con el desarrollo de la semiosis infinita, pues se desenvuelve en la vida misma de los signos que la representan a la vez que la construyen (p. 133).

Por lo tanto, si la relación entre lo que puede ser dicho y la realidad no es necesaria, sino que cada nueva formulación va contribuyendo a su construcción, renovándola a la vez que reproduciéndola, también podemos reconocer aquí una dimensión antagónica, de enfrentamiento entre discursos por la construcción de la realidad, antagonismo que resulta inherente tanto a la producción de discursos como de la realidad.

De este modo, sobre esa realidad es posible decir cosas diferentes y, así, construirla de modos diferentes también. Esta dimensión polémica de la constitución de la realidad es lo que Triquell y Ruiz denominan "lo político" de los discursos (2014, p. 134). Lo político, en una dimensión analítica, podría ser definido entonces como el antagonismo propio, inherente, de lo social, toda vez que la realidad está siendo construida continuamente, a partir de tensiones y disputas que, en la semiosis, adquieren la forma de discursos.

En el arte, dentro del cual incluimos al cine, esta dimensión política adquiere la posibilidad de tornarse específicamente conflictiva, ya que algunas obras, por lo menos, apuntan a sustituir "las continuidades y progresiones características del modelo narrativo

$5 \quad$ Nos referimos a los espacios del patio del colegio donde realiza educación física y también a la pileta en la que los estudiantes tienen natación, además de los espacios áulicos tradicionales. Todo parece indicar que la escuela a la que asiste Martín es de gestión privada. No obstante, la consideramos pública en tanto institución del Estado y parte del ámbito de lo público-colectivo, en oposición a lo íntimo, privado y/o familiar. 
y empático por una forma rota que apunte a sacar a la luz las tensiones y contradicciones inherentes a la presentación de las situaciones y a la manera de formular sus elementos, motivos y salidas" (Rancière en Triquell y Ruiz, 2014, p. 136).

Ausente se inserta así, siguiendo a Eliseo Verón (1987, p. 121 y ss.) en una red de discursos que la antecede, una red de semiosis, que la determina y a la que, al mismo tiempo, ayuda a construir. Nos gustaría plantear aquí que, en gran medida, algo en las obras de Berger podría ser identificado con esa forma rota a la que alude Rancière y que, en nuestro trabajo, en particular, ponen en evidencia ciertos conflictos (sociales) vinculados con la ESI, a partir de los conflictos narrativos del filme y, sobre todo, de los modos en que son construidos audiovisualmente.

Así, siguiendo la propuesta de Triquell y Ruiz (2014), el conflicto que nos interesa en este trabajo surge, más allá de lo narrativo, en la relación de este discurso fílmico con la realidad. Sostenemos que la potencialidad en términos de generación de conflictos en los filmes de Berger, y sobre todo en Ausente, no surge desde dentro de la trama principalmente, sino de la forma en que están construidos los planos y las miradas sugeridas. Además, pensando en la ESI, esta potencialidad está dada por fuera del discurso (es decir, más allá de él como unidad de sentido) en las instancias de recepción consideradas desde una didáctica de la comunicación y habilitadas, en todo caso, por la narrativa del filme pero, sobre todo, por este uso particular de las cámaras y las miradas en la diégesis. Para decirlo de otro modo, ¿́puede el filme, sin pretenderlo, darnos alguna pista sobre lo que puede estar ocurriendo en las escuelas con el complejísimo proceso de implementación de la Ley de ESI? Para buscar respuestas a este interrogante, nos proponemos profundizar en la propuesta narrativa (su historia) y la enunciativa (el modo en que está contada) (Ilardo, 2014) del filme Ausente para, hacia el final, volver sobre estos interrogantes iniciales.

\section{El conflicto narrativo}

Un estudiante finge una lesión ocular y su profesor lo acompaña al hospital. Luego, asegura no tener llave de su casa, en la que su abuela, único familiar, no se encuentra; ni conocer la dirección de la casa de su compañero donde se suponía iba a pasar la noche; no tener ni su mochila ni su celular para poder comunicarse con amigos o familia. Después de muchos intentos y sendos fracasos, Sebastián, el docente, no tiene opciones y toma una decisión movido por la preservación y el cuidado del menor-estudiante: preservar a Martín de posibles dificultades y alojarlo en su hogar por esa noche.

- Mirá, te venís a mi casa. Te armo algo en el living. Igual sabés que me puedo meter en problemas, ¿no? Pero no te puedo dejar en la calle o llevarte a la policía. Porque la pasarías mal vos y porque no, porque sería una cagada. Lo que sí te pido es que no se lo digas a nadie. Porque vos sos menor y de verdad me puedo meter en problemas llevando a un alumno a dormir a mi casa. ¿Entendés eso, no? Bueno, vamos, levantá el vidrio. (Berger, 2011, 23:20min)

En este fragmento decisivo, en el auto de Sebastián, aparecen dos elementos importantes: la responsabilidad y la duda vinculadas ambas a un rol. Si bien los motivos para 
pedirle a Martín que no diga nada parecieran tener que ver con la legalidad ("sos menor"), es más evidente que la decisión de darle resguardo por una noche está fundada en un acto de cuidado/protección, probablemente atado a un rol (alumno-docente). Podemos acordar que lo que media en esta situación de necesidad de resolución del estado de Martín es la institución Escuela. Sin la Escuela de por medio, este conflicto narrativo de la película no tendría sustento: sin dudas la (posibilidad de la) ilegalidad al alojar a un menor en su hogar existiría, pero no habría ninguna obligación "ética" de acogerlo, ninguna relación (pedagógica) que admitiera la "preocupación" por el otro, y, por lo tanto, desde la óptica del docente, de la necesidad de asumir el riesgo. Si entre ambos sujetos no mediara la relación estudiante-docente, probablemente Martín debería resolver en soledad dónde pasar la noche y esto no sería un dilema para Sebastián.

Durante la primera parte de la película casi no intervienen otros personajes; la historia es eminentemente de ellos dos. Durante esa noche (y más adelante, cuando Martín regresa a devolver una remera), la mirada de los otros trae a escena su preocupación y la ambigüedad de la situación generada. La forma en que la vecina y el portero observan la situación de este estudiante (menor de edad) pernoctando en lo de Sebastián pareciera hacer desaparecer los roles (pedagógicos) que los unen en beneficio de un adelgazamiento de ese momento: se trata probablemente de un vínculo sexual y, por lo tanto, fuera de la ley. Así, si la Escuela es la sede de la responsabilidad ética frente a la minoridad, los otros (ajenos a la Escuela) son la sede de la duda y la sospecha.

A partir de allí, Sebastián encuentra nueva información y completa la historia: Martín vive con sus padres y no con su abuela y quedarse a dormir en su casa era algo que él buscó y manipuló para que sucediera. Luego, se encuentra en la calle con Martín y le pregunta sobre lo sucedido.

-¿¿Qué pasó?

-Perdón profe.

-Así que vivís con tus papás. Nunca te entró nada en el ojo. ¿Puedo entender un poco qué es lo que querés? ¿Por qué mentiste así?

-Se suponía que mi mamá no se iba a enterar y no iba a armar semejante quilombo.

-¿Pero por qué me mentiste así? Me hubieses dicho que tenías un problema

y te podría haber ayudado de alguna forma...

-No sé, pensé que si me metía en su casa podía pasar algo...

-¿̇Algo qué? (Berger, 2011, 51:30 min)

Ante esa insinuación, Sebastián lo golpea. La agresión física, desenlace de otro de los nudos de conflicto de la narración, sin dudas es la manifestación del enojo. Lo que no se explicita es el motivo del enojo del profesor: puede ser por la insinuación de que algo podía pasar entre ellos; puede ser por la "emboscada" (y por la posterior confesión); puede ser por la osadía. Después de esto, ambos personajes solo se cruzarán de lejos en la escuela; median entre ellos amenazas de denuncias cruzadas. Frente a estas amenazas, el conflicto (narrativo) que perturba al docente se resuelve con la muerte accidental del 
estudiante. Esto da lugar al conflicto final (subjetivo): el del deseo (sexual) del profesor y el de la culpa por su reacción. Con la muerte del estudiante, ni uno ni otro encuentran posibilidad de satisfacción más que en un reencuentro onírico-fantaseado en el que Sebastián dice: "Te quería pedir perdón. Perdoname" y luego llora. Con esas palabras, confesión de culpa y posterior alivio, llega el fin 6 .

\section{La lectura de Sebastián y su novia}

A diferencia de otros filmes de Berger, en Ausente no encontramos imágenes del pequeño reproductor infantil de imágenes que en el cortometraje "El reloj" (Berger, 2008) llaman ViewMaster ${ }^{7}$, pequeño objeto fetiche en el cine de Berger. No hay tampoco esa fluida circulación de objetos que caracterizan otras películas anteriores y que son fundamentales, por ejemplo, en Plan B (Berger, 2009).

En Ausente Martín usa una remera de Sebastián, su desodorante, el sofá de su living para dormir. Luego, deja un papel en su parabrisas: "Perdón, Profe, no quería dormir en mi casa y le mentí" (Berger, 2011, 45:50min). Sin embargo, no es un vínculo que admita un intercambio fluido de objetos, más allá de los saberes y conocimientos propios de la relación docente-alumnos, justamente porque su vínculo está basado en aquello que es compartido de antemano y de manera pública: ese rol estudiante-docente. Diferente pareciera ser el caso de los protagonistas de Plan B (Berger, 2009) o de Hawaii (Berger, 2013), quienes en gran medida construyen su relación a partir del trueque de objetos.

Deseamos detenernos, sin embargo, en un tipo de intercambio específico que tiene lugar en Ausente. A diferencia de sus otros filmes, aquí hay una circulación interesante de un objeto que no se produce entre los personajes principales, sino entre Sebastián y su novia.

Sebastián está leyendo a lo largo de la película un libro cuyo título sólo alcanzamos a ver inmediatamente después de la escena de la muerte de Martín. Se trata de El libro de los amores ridículos 8 , de Milan Kundera (2005). Recién allí la cámara nos deja verlo, con un

6 Muchas de las críticas y comentarios del filme resaltan que esta escena final es la prueba del amor/ deseo correspondido, que por miedo Sebastián no logra actuar. Para nosotros, esta suposición sobre los motivos del personaje no es central. En todo caso, lo que dice y lo que genera en él ese pedido de disculpas, sí lo son. Frente a su accionar, lo que pareciera preocupar a Sebastián no es concretar una relación sexual frustrada, sólo asistimos a un beso en este final, sino hacer llegar las disculpas por una falta cometida. Esa falta está en el rechazo a la franqueza de Martín y en el golpe: en la violencia de esos gestos. Frente a esa disculpa final, tardía y en parte reparadora, nos preguntamos: ¿acaso no restituye el carácter pedagógico de esta relación, más allá de su deseo amoroso/sexual presente o ausente?

7 En la web podemos encontrar el sitio oficial de este producto-juguete en http://www.view-master.com/ en-us/index.html (última consulta: abril de 2015) y en otro lugar una definición sobre lo que este objeto es: "View-Master es un dispositivo visualizador de discos con 7 imágenes estereoscópicas. (...) Aunque el View-Master gira 14 imágenes, realmente solo hay 7 imágenes estereoscópicas, 2 imágenes son vistas simultáneamente -una por ojo- simulando así la sensación de profundidad en la percepción binocular." Tomado de http://es.wikipedia.org/wiki/View-Master (última consulta: abril de 2015).

8 Es imposible no asociar ese adjetivo del título con la muerte de Martín, producto de un accidente doméstico tonto e imprevisible. 
plano desde la izquierda de Sebastián recostado, abriendo el libro. Algunas escenas más adelante, la novia de Sebastián habla también de un libro; como espectadores estamos habilitados a suponer que se trata del mismo. Ella dice que no sabe si le gustó o no; que no sabe si lo recomendaría o no; que le parece que le dejó cosas sin contar; que la historia está buena, pero se va por las ramas, no le cuenta lo que le gustaría que le contara; que le parece que la idea del libro es dejar lagunas "pero yo sentí como que le falta algo", agrega (Berger, 2011: 1:10:00). Ella queda fuera de algo de lo que se narra en ese libro, así como queda en ese momento afuera del estado de (confusión y tristeza de) Sebastián.

Ninguno de los siete relatos que componen el libro tiene una similitud evidente con la historia de Sebastián y Martín. Ciertamente algunos de ellos dan cuenta de vínculos amorosos y generalmente sexuales entre sujetos en los que la idea de lo ridículo cuestiona las motivaciones de los personajes en tanto puras y en tanto propias. Kundera ensaya posibilidades, motivos y excusas para hacer más complicados los vínculos amistosos, sexuales, amorosos en las historias de sus personajes:

[...] De pronto comprendí que no fue más que una ilusión haber pensado que cabalgamos nosotros mismos en nuestras propias historias y que dirigimos su marcha; que en realidad es posible que no sean, en absoluto nuestras historias, que es más probable que nos sean adjudicadas desde afuera; que no nos caracterizan; que no podemos responder de su extrañísima trayectoria; que nos raptan, dirigidas desde otra parte por fuerzas extrañas (Kundera, 2005, p. 52) (cursivas en el original).

Una historia producto de una trayectoria de la que no somos los dueños ni los que la dirigen. Berger pareciera afirmar una y otra vez en sus películas que no le interesan las historias amorosas consolidadas: lo suyo es la exploración de las situaciones iniciales, de encuentro. Para hacerlo, además, no le basta con un abanico de historias con estos elementos comunes. Planta la cámara y genera miradas de un tipo particular que, siguiendo a Mulvey (2001), invitarían al espectador a interrogarse a sí mismo en torno a lo que está mirando. ¿Y si fuera real que no cabalgamos nuestras propias historias, sino que estas son dirigidas desde otra parte por fuerzas extrañas? (Kundera, 2014, p. 52) ${ }^{9}$.

\section{Algunas elecciones de la cámara}

Es evidente que Berger juega desde el inicio con la dificultad inicial de inscribir los planos detalle de los títulos en alguna serie conocida por el espectador. Esos fragmentos de cuerpo masculino y desnudo desde el comienzo mismo del filme marcarán cierto derrotero propio del director: colocar la cámara y dar a ver al espectador un cuerpo masculino como objeto de deseo (aunque la serie médica sea la respuesta final de esa escena, en la forma de la revisión para el pase a la pileta). Esto es lo que Berger hace: construir a Martín (y a

9 Al formular estos interrogantes solo deseamos consolidar una hipótesis de trabajo en relación al personaje de Sebastián y bajo ningún punto de vista sentar una posición en torno a la naturaleza y/o el origen de aquello que es movilizado por y que moviliza la pasión y el deseo en hombres y mujeres. Esa preocupación excede con amplitud los objetivos de este trabajo. 
otros de los estudiantes compañeros de él) como objeto de deseo ante la mirada de su profesor y eventualmente, ante la nuestra como espectadores.

A tal fin, hay dos usos de la cámara que, si bien similares entre sí, deseamos distinguir. El primero tiene como sujeto de la mirada a Martín. Tanto en la piscina al comienzo y al final de filme, como durante la noche en el departamento del docente, Martín fija su mirada en otros (compañeros de la escuela/ de la piscina, Sebastián) y nosotros, como espectadores, estamos en algunos momentos frente a él (Martín mira ligeramente hacia los costados de la cámara, casi directamente hacia ella y hacia nosotros, en más una oportunidad) y luego Berger nos muestra lo que está mirando: adoptamos su perspectiva y compartimos su mirada. El segundo tiene a Sebastián como sujeto de la mirada y a Martín como el objeto. No son estrictamente cámaras subjetivas que se correspondan con la mirada del profesor (en la piscina, Martín mira ligeramente hacia la izquierda de la cámara, cuando intercambian miradas; en el departamento, vemos ligeramente el hombro de Sebastián mientras observa a Martín durmiendo en el comedor). Como espectadores, estamos apenas afuera de ese intercambio de miradas que se hace explícito hacia el final (Berger, 2011, 80min y ss.), aunque asistiendo a él desde un lugar privilegiado.

Sea porque compartimos el campo visual de Martín (más general, que incorpora a varios personajes); sea porque compartimos (casi de manera perfecta) el punto de vista de Sebastián sobre Martín, en uno y en otro caso, somos invitados, en tanto espectadores, a mimetizarnos y contemplar lo que ellos miran. En más de una oportunidad, en cambio, eso que se ve es Martín, que devuelve la mirada (casi directamente) a la cámara, interpelándonos desde dentro de la diégesis (cfr. Casetti y Di Chio, 1991).

Sebastián, en cambio, es mostrado a lo largo de todo el filme o bien de costado o bien desde atrás. Este es el punto de vista que se privilegia sobre él. Hacia el final, luego de la muerte de Martín, comenzamos a ver lo no visto antes. Las cámaras que lo acompañan desde fuera del auto, desde atrás en el baño frente al espejo dan lugar a los flashbacks, incorporados al tiempo presente. La cámara lo muestra a Sebastián en su auto (Berger, 2011, 67 min), una vez más, desde afuera a la izquierda. La cámara se mueve unos centímetros hacia atrás y gira levemente hacia adelante. Eso da lugar a que en el asiento del acompañante, antes libre, ahora esté sentado Martín. Es la mañana siguiente, cuando se despiden al llegar a la escuela, luego de que Martín durmió en casa de su profesor. La escena muta así, tan solo por un movimiento de cámara, de un instante reflexivo de Sebastián, a un recuerdo de los momentos compartidos ${ }^{10}$.

10 Un segundo ejemplo lo encontramos en Berger, 2011, 71 min: Sebastián se mira en el espejo, en la pileta. Primer plano de su rostro que mira el agua. Luego, primer plano/ plano medio suyo frente al espejo. Parece recordar, arrepentirse, reflexionar. Corte directo y en su lugar, frente al espejo, ahora está Martín. Es un flashback de recuerdo: volvemos al momento en que a Martín supuestamente le entró algo en el ojo. La cámara, de costado, es un primerísimo primer plano de ellos dos, mientras Sebastián mira el ojo de Martín. Sus rostros están muy próximos uno del otro, frente a frente. Sebastián se mira al espejo y cierra la escena como la empezó (al igual que la del auto que ya mencionamos). Son escenas circulares, de recuerdo (sólo la ropa de Sebastián cambia), en los mismos espacios. 
Así, mientras Sebastián es mostrado como objeto (de deseo, de tensión sexual) solamente desde la perspectiva de Martín y, por lo tanto, no mira nunca a cámara, no interpela al espectador, Martín es mostrado como el objeto de la mirada de Sebastián en más de una oportunidad pero también como sujeto de una mirada que tiene al docente como destinatario, pero también a otros (compañeros, sobre todo). Martín se transforma en un otro que provoca doblemente: a partir de lo que mira (cuerpos masculinos) y a partir de mirarlo al espectador (casi) directamente a los ojos. Por lo tanto, en recepción, y volviendo a Mulvey (2001), Ausente propone la identificación con la mirada y el personaje de Sebastián: asistimos a sus dudas, acompañamos sus decisiones, miramos lo que él mira, a partir de travellings o cámaras fijas. ¿Es la férrea decisión presente en un adolescente, algo censurable por parte de los adultos? ¿Estamos preparados para enfrentar un deseo que se explicita de este modo? A partir de la construcción de las miradas de los personajes entre sí, de lo dado a ver por las cámaras y de la focalización interna (Casetti y Di Chio, 1991, p. 240; Ilardo, 2014, p. 24-25), Ausente nos invita a que ocupemos el lugar de Sebastián y transitemos lo que él sufre.

\section{Ley de Educación Sexual Integral y Sebastián}

La Ley de ESI (Nro. 26.150) plantea en su artículo primero que

Todos los educandos tienen derecho a recibir educación sexual integral en los establecimientos educativos públicos, de gestión estatal y privada de las jurisdicciones nacional, provincial, de la Ciudad Autónoma de Buenos Aires y municipal. A los efectos de esta ley, entiéndase como educación sexual integral la que articula aspectos biológicos, psicológicos, sociales, afectivos y éticos (Ley 26.150, artículo 1).

Si bien no avanza en relación con los contenidos que la ESI debería incorporar en cada escuela, prevé que los lineamientos generales sean definidos por una comisión interdisciplinaria de especialistas en la temática (artículo 7). En el artículo noveno la Ley propone espacios de formación incorporados en las escuelas, que tengan como destinatarias a las familias de los estudiantes y que respondan, entre otros, al siguiente objetivo: "Promover la comprensión y el acompañamiento en la maduración afectiva del niño, niña y adolescente ayudándolo a formar su sexualidad y preparándolo para entablar relaciones interpersonales positivas" (Ley 26.150, artículo 9, inciso b).

De esta forma, si bien no fija contenidos, la Ley tampoco sanciona ni prohíbe prácticas (al menos a priori). La escuela debería partir de las prácticas de los estudiantes y acompañarlos en la formación de su sexualidad y en la preparación de relaciones (afectivas y amorosas, entre otras) positivas. En este sentido, en Ausente, la figura de Sebastián y metonímicamente, la de la escuela toda, da cuenta de pasos titubeantes, que, a la vez que avanzan, parecieran retroceder.

Sebastián atraviesa el filme en conflicto. Podemos identificar tres grandes secuencias en este sentido. Primero, por tener que resolver qué hacer con Martín cuando parece que no tiene lugar dónde volver a dormir. Segundo, cuando se entera que todo lo que ocurrió 
fue decidido y buscado de ese modo por Martín. El golpe que cierra esa secuencia abre un nuevo nudo, en el que Sebastián se enfrenta a sí mismo. La resolución final la encuentra en el vestuario de la piscina, con una figura de Martín que regresa para que él pueda disculparse.

A lo largo de la primera secuencia, podríamos acordar que Sebastián se ubica a sí mismo y privilegia su función como docente y desde ella ejerce las acciones esperadas: asume una actitud de protección frente al adolescente, da solución a sus conflictos y lo acompaña, a pesar de los riesgos y las sospechas que esto pueda atraer sobre él.

El segundo conflicto, y sobre todo el modo en que Sebastián lo resuelve, desde el enojo y con violencia, lo encuentra mal parado: ese rol temático que ha actuado hasta aquí se cae y queda (al) descubierto. Sebastián ya no comprende ni acompaña al estudiante, porque se ve implicado en la situación. No puede tomar la distancia necesaria para establecer la reflexión necesaria; queda comprometido entre el engaño, el enojo y eventualmente su deseo. Martín reacciona defensivamente, con una amenaza. Y el nudo narrativo que se abre allí se cierra, casi en forma automática e independiente, con la ridícula muerte de Martín.

Así, el conflicto final es de Sebastián consigo mismo. Ya lo señalábamos antes: no importa si su angustia es en relación con su sexualidad, en relación con la pérdida del objeto de deseo/ amoroso, si es simplemente culpa o una mezcla de todo lo anterior ${ }^{11}$. Su pedido de perdón es lo que habilita su descarga, las lágrimas y, finalmente, el cierre.

\section{Últimas reflexiones}

La cámara lo espera dentro de la pileta de natación. Vidrios rotos, unos pies que se apoyan en el descanso de la escalera, delante de la cámara. Baja los escalones. Llega abajo, y la cámara sigue a la altura de la cintura. Nos deja ver que su mano está ensangrentada. Caen unas gotas. Sebastián se sienta. La cámara queda frente a su rostro. La luz comienza a cambiar, la estancia se ilumina. Él mira una vez más hacia el costado de la pileta, hacia el lugar por el que Martín ha pasado más de una vez, hacia el vestuario. La luz cambia. Él está ahí sentado otra vez, entre sus compañeros, iluminado por esta nueva luz. Lo mira y sonríe. Martín se para, mirando a Sebastián continuamente. Su mirada lo sigue. Vemos a Martín que entra al vestuario. Sebastián lo sigue. Caminan por delante la cámara, buscándose y perdiéndose. La cámara está fija, lo que cambia es el foco: va tomando a uno y a otro, alternativamente, al tiempo que aparecen y desaparecen delante de ella. Sebastián lo busca.

Desgrabación Ausente (Berger, 2011, 77 min y ss.)

11 En el presente análisis no consideramos aportes de la teoría queer y de los estudios de género en particular que podrían ser pertinentes, sobre todo por una cuestión de espacio. El artículo de Stuart Hall ¿Quién necesita identidad? (2003) resulta un punto de partida ineludible. Pensamos, además, que los aportes de Leo Bersani (1998), por ejemplo, podrían ser pertinentes y agradecemos al evaluador del artículo su sugerencia en este sentido. En efecto, la estabilización de una identidad o su desestabilización, como podría ser el caso de Sebastián, resultan siempre una operación política y, por lo tanto, fundamental pedagógicamente (1998, p. 15 y ss.). Puede confrontarse, por ejemplo, la noticia publicada en la sección Sociedad del Diario Página 12, de Argentina, por Mariana Carbajal, el día lero de Octubre del corriente año, titulada "Los docentes que van abriendo sus cabezas". Sin dudas, resultan exploraciones a considerar en futuros análisis. 
Los procesos de implementación de la Ley 26.150 en Argentina han sido y están siendo complejos y múltiplemente heterogéneos. Hay toda una serie de investigaciones en curso que dan cuenta, por un lado, de la necesidad de profundización en este camino (cfr., por ejemplo, Molina, 2014) y por otro, de las dificultades encontradas hasta aquí, sobre todo en el trabajo con los docentes (cfr., entre otros, Boccardi, 2014). Por eso nos parece relevante sumar aportes provenientes desde otros ámbitos, que analicen discursos en circulación y que consideren especialmente entre sus destinatarios a los docentes y a los formadores de docentes.

En este sentido, deseamos ahora dar un cierre (provisional, por cierto) a la argumentación presentada hasta aquí en relación con la película Ausente, en un doble sentido. En tanto discurso, objeto de análisis en sí mismo, por las particularidades que ya hemos señalado. Y en su relación con la realidad a la que representa y, a su vez, construye.

Lo planteábamos al comienzo como una suerte de hipótesis de trabajo, que iba a resultar imposible refutar o refrendar aquí: la película bien podría funcionar como una metáfora de aquello que en las escuelas no logra procesarse en relación con la Ley de Educación Sexual Integral. Como adultos-docentes, podemos partir de una postura bienpensante, de derechos incluso, en nuestro trabajo en las escuelas. Esta posición, no obstante, es posible que encuentre su límite cuando se reconoce/se topa con que el otro es un sujeto de sexualidad y la ejerce, y justamente cuando ese otro es un joven/ un adolescente. Ese, al menos, es el límite para Sebastián.

A partir de un trabajo metodológico de análisis de discursos audiovisuales (Triquell, coord, 2011 e Ilardo, 2014), de la puesta en juego de reflexiones teóricas cercanas al cine (Mulvey, 2001) y a la semiótica (Triquell y Ruiz, 2014) y considerando como horizonte de destino de estas reflexiones el trabajo docente, especialmente en Comunicación Social, hemos intentando proponer un recorrido posible de análisis de un filme para pensar luego su relación con un aspecto de la realidad educativa de nuestro país.

A partir del reconocimiento de la dimensión política inherente en la relación de los discursos con la realidad, hemos intentado hacer explícito que la elección de determinadas películas para su trabajo en el espacio áulico también contempla una dimensión de lo político. La didáctica de la comunicación aquí estaría operando para permitir que nuestro análisis contemple el relato en el filme, pero también la forma en que ese discurso está construido y los modos en que podemos operar con él en nuestras propuestas didácticas. Lo decíamos antes: la potencialidad pedagógica de una obra como las de Berger radica justamente en la operación didáctica que, como comunicadores, podemos realizar sobre esa obra para hacerla estallar y acercarla a nuestros intereses profesionales, a partir de la complejidad y conflictividad inherentes a su planteo. Esta complejidad y conflictividad ameritan ser incorporadas en las escuelas para su debate, y filmes como el de Berger lo habilitan doblemente: a partir del juego de miradas que proponen tanto como del relato que ofrecen. 
Se disculpa. Sebastián se queda en su lugar, apoyado en los lockers, de espaldas. La cámara una vez más lo toma de costado, desde la izquierda, en un primer plano. Sonríe y llora. La música es más leve: la guitarra acompaña el momento de la ruptura de lo que fue y de las contenciones/ barreras derrumbadas. La imagen vuelve a ser oscura: estamos en el momento presente otra vez. La música se detiene lentamente. Da lugar a los créditos finales.

Desgrabación Ausente (Berger, 2011, 83 min y ss.).

\section{Bibliografía}

BERSANI, L. (1998). Homos. Buenos Aires: Manantial.

BOCCARDI, F. (2014). Acerca de la integralidad. Una lectura semiótica de los fundamentos de la educación sexual integral. En AMMANN, Ana B. y otras (Eds). Sujetos emergentes y prácticas culturales. Experiencias y debates contemporáneos. Córdoba: Ferreyra Editor. Págs. 219-228.

CASETTI, F. y DI CHIO, F. (1991). Cómo analizar un filme. Barcelona: Edit. Paidós.

ECO, U. (1987). Lector in fabula. Barcelona: Lumen.

GARZA, Norma (2002). José Saramago o la mirada de la invisibilidad. En COHEN, E. y MARTÍNEZ DE LA ESCALERA, A. M. (Coords.). Lecciones de extranjería. Una mirada a la diferencia. México: Siglo XXI Editores. Págs. 169-179.

HALL, S. (2003). ¿Quién necesita identidad? En HALL, S. y DU GAY, P. (Comps.). Cuestiones de identidad cultural. Buenos Aires: Amorrrortu.

ILARDO, C. (2014). Herramientas teórico-metodológicas para pensar los discursos audiovisuales. Acerca de la metodología empleada, en ILARDO, C. y MOREIRAS, D. Mirando 25 Miradas. Córdoba: Universidad Nacional de Córdoba. Facultad de Artes. Centro de Producción e Investigación en Artes; Facultad de Filosofía y Humanidades. Secretaría de Extensión. Pp. 16-26. Recuperado del repositorio institucional de la UNC el día 22 de noviembre de 2015. Disponible en https://ansenuza. unc.edu.ar/comunidades/bitstream/handle/1 1086.1/865/mirando\%2025\%20miradascompleto. pdf?sequence $=1$

KUNDERA, M. (2005). El libro de los amores ridículos. Buenos Aires: Tusquets.

MOLINA, G. (2014). Género y sexualidades entre estudiantes secundarios. Un estudio etnográfico en escuelas cordobesas. Buenos Aires: IDES - Miño y Dávila Editores.

MULVEY, L. (2001). Placer visual y cine narrativo. En WALLIS, B. Arte Después de la Modernidad. Nuevos Planteamientos en torno a la Representación. Madrid: Editorial Akal. Pp. 365-377.

NABOKOV, V. (1987). Lolita. Barcelona: Anagrama.

REY, G. (2007). Los relatos periodísticos del crimen. Bogotá: Centro de Competencia en Comunicación para América Latina - Fundación Friedrich Ebert Stiftung. Pp. 7-20.

TRIQUELL, X. y RUIZ, S. (2014). La dimensión política de los discursos sociales. Revista de Signos y Sentidos n. ${ }^{\circ}$ 15. Santa Fe: Universidad Nacional del Litoral. Pp. 125 138.

TRIQUELL, X. (coord.) (2011). Contar con imágenes. Córdoba: Editorial Brujas.

VERÓN, Eliseo (1987). La semiosis social. Barcelona: Gedisa. 
Documentos consultados

Congreso de la Nación Argentina. Ley de Educación Sexual Integral Nro. 26.150. Octubre de 2006.

Filmografía

BERGER, Marco (Director) (2008). El reloj. [Cortometraje]. Argentina: Marco Berger.

(Director) (2009). Plan B. [Película]. Argentina: Rendez-vous Pictures y Oh My Gomez! Films.

(Director) (2011). Ausente. [Película]. Argentina: Instituto Nacional de Cine y Artes Audiovisuales (INCAA) y Oh My Gomez! Films.

(Director) (2013). Hawaii. [Película]. Argentina: La Noria Cine y Universidad del Cine.

DOS SANTOS, Alexis (Director) (2006). Glue. [Película]. Argentina: Diablo Films.

EYRE, Richard (Director) (2006). Notes on a scandal. [Película]. Reino Unido: Fox Searchlight Pictures - DNA Films.

FAVIO, Leonardo (Director) (1975). Nazareno Cruz y el lobo. [Película]. Argentina: Choila Producciones Cinematográficas.

PUENZO, Lucía (Directora) (2007). XXY. [Película]. Argentina: Historias Cinematográficas Cinemania.

SOLOMONOFF, Julia (Directora) (2009). El verano de la boyita. [Película]. Argentina: Travesía Productions y Domenica Films. 